$\xi=1$

\title{
Job satisfaction among nurses in Al-Qassim hospitals and primary health care centers, Saudi Arabia, 2016
}

\author{
Hassan Al-Takroni ${ }^{1}{ }^{*}$, Adel Al-Hindi ${ }^{2}$, Kavija Joshva ${ }^{3}$, Awad Al-Harbi ${ }^{4}$ \\ ${ }^{I} R N$, Ministry of Health of Saudi Arabia, Nursing administration, Al-Qassim \\ ${ }^{2} R N$, BSN, Ministry of Health of Saudi Arabia, Nursing administration, Al-Qassim \\ ${ }^{3} R N$, MD, Nursing Educator, Maternity and Child Hospital, Al-Qassim \\ ${ }^{4}$ RN, BSN, Ministry of Health of Saudi Arabia, Nursing Director, King Saud Hospital, Al-Qassim \\ *Corresponding author E-mail: haltakroni@moh.gov.sa
}

\begin{abstract}
Background: Job's satisfaction consists of a feeling of well-being, resulting from the interaction of several occupational aspects, and may influence the worker's relationship with the organization, clients and family. Hence, it becomes important than the quality of nursing care to reflect on this topic in depth. The current nursing shortage and high turnover are of great concern in the Kingdom of Saudi Arabia (KSA) because of its impact on the efficiency and effectiveness of any health-care delivery system.

Objectives: To assess the level of job satisfaction among staff nurses working in Ministry of Health(MOH) hospitals and primary health care centers (PHC) in Al Qassim region. To prepare and implement an action plan according to the findings from the study.

Methods: A descriptive cross- sectional design is utilized in the current study. The study was conducted between 5542 nurses working in 20 hospitals and PHCs in Al Qassim region. Response rate is $18 \%$ and 1037 questionnaires were analyzed using factor analysis and correlation.

Findings: Overall results show that the job satisfaction is found to be averagely satisfied. Accommodation level, administration, work condition, recognition, co-workers communications, educational activity, payment, vacation and leave are used to determine the job satisfaction. There is no correlation between demographic variables and job satisfaction among the staff nurses. Most of the staffs were not satisfied with the workload. Additionally, most of the nurses not satisfied with their weekly off, and they are not happy with their annual allowance.

Conclusion: This study concluded that the majority of the nurses participated in the study are averagely satisfied in their job. Therefore, the administration needs more interventions to build the satisfaction of staff nurse for better nurse retention.
\end{abstract}

Keywords: Job Satisfaction; Job Stress; Nurses; Working Environment Nursing; Nurse Shortage; Nurse Retention.

\section{Introduction}

Job satisfaction in staff nurses should be of great concern to any organization. Nurses hold the majority of positions in most of the health care settings, and replacement of licensed personnel is costly and time consuming. Nurse shortages and high nurse turnover continue to be among the most vexing problems for healthcare systems worldwide. These two issues have become of great concern to many countries, including KSA(Kettle, 2002).

Employee job satisfaction is the fulfillment, gratification, and enjoyment that come from work. It is not just the money or the fringe benefits, but the feelings' employees receive from the work itself. The most-used research definition of job satisfaction is by Locke, who defined it as "a pleasurable or positive emotional state resulting from the appraisal of one's job or job experiences." Work satisfaction is comprised of intrinsic and extrinsic factors. Intrinsic factors are those internally derived and include personal achievement, sense of accomplishment, and prestige. Extrinsic factors are those derived from factors within the practice environment and include pay and benefits, working conditions, and resources(Asegid, Belachew, \& Yimam, 2014).

The United States of America(USA) has the highest rate of job dissatisfaction, at 41 per cent, followed by Scotland, at 38 per cent, the United Kingdom, at 36 per cent, Canada, at 33 per cent and Germany, at 17 per cent (Lu, While, \& Louise Barriball, 2005). Another study in USA, found significant differences between hospital and nursing unit characteristic and the nurse work environment in the rural and urban nursing units. Both nurse's unit characteristic and the work environment were found to have a significant influence on nurse job satisfaction and turnover rates (Baernholdt \& Mark, 2009).

In United Kingdom, a study found stress and leadership issues continue to exert influence on dissatisfaction and turnover for nurses also the level of education achieved, and pay were found to be associated with job satisfaction(Coomber\& Barriball, 2007). In Italy, a study found that the nurses satisfied with job content, professional relationships, responsibly, independence and professional growth, relationship with patient and their families, relationship with coordinators. Even so, they were not satisfied with coordinator management style, activity programming and organization relationships with doctors, and relationship with a patient(Cortese, 2007). A study in Malaysia found the nurses' job satisfaction moderate in sex facets of job satisfaction with supervisor, job variety, closure, compensation, co-workers and human-resource management policies. Therefore, exhibits perceived lower level of their intention to leave the hospitals(Alam\& Mohammad, 2010). In Saudi Arabia, several research studies that have been conducted in 
various geographical regions have examined job satisfaction among combined cohorts of Saudi and non-Saudi nurses working in both the private and public healthcare sectors. These studies included a variety of related variables, such as job satisfaction and organizational commitment, leadership style, hospital performance and job satisfaction, as well as burnout and intention to stay(AlAameri, 2000),(Al-Ahmadi, 2009), (AL-Dossary, Vail, \& Macfarlane, 2012),(El Gilany \& Al Wehady, 2001), (Mitchell, 2009),(Abualrub\& Alghamdi, 2012), (Zaghloul, Al-Hussaini, \& Al-Bassam, 2008). According to these studies, job dissatisfaction was mainly attributed to organizational commitments, payment rewards, operating conditions, social views, company policy, administration, hospital policies and recognition.

High nurse turnover is one of the threatening problems faced by the administration nowadays. This study identifies and explores the level of job satisfaction among staff nurses working in $\mathrm{MOH}$ hospitals and PHC in $\mathrm{Al}$ Qassim region, KSA that will bring into light the reason for high turnover and the recommendation, which is formulated, on the light of the study can promote the retention of the staff nurses. Therefore, the nursing administration in $\mathrm{Al}$ Qassim region, KSA wants to identify that factors which are leading to dissatisfaction and subsequently, make an action plan, which will bring the expected results in the region.

\section{Definitions}

All the feelings that an individual has about his job (Gruneberg, 1976)(Lu et al., 2005).

A function of satisfaction with the various elements of the job(Herzberg and Mausner, 1959)(Lu et al., 2005).

The individual matching of personal needs to the perceived potential of the occupation for satisfying those needs (Kuhlen,1963)(Lu et al., 2005).

Need fulfillment, that is, whether or not the job met the employee's physical and psychological needs for the things within the work situation (Worf, 1970)(Lu et al., 2005).

\section{Methodology}

The aim of the study is to implement an action plan according to the findings from the study. A descriptive cross-sectional study conducted in $\mathrm{Al}$ Qassim hospitals and PHC, KSA. Although many scales measure job satisfaction among nurses this study was based job satisfaction measure according to a subjective feeling of the nurses and after literature review, the measure was developed. A "stratified convenience" sampling design had used. After a pilot test for reliability and validity, the researcher distributes a selfadministered questionnaire with explanatory statement through Email (online survey) to 5542 nurses who is the total population of nurses working in $\mathrm{MOH}$ hospitals and $\mathrm{PHC}$ in $\mathrm{Al}$ Qassim region. Those include different nationalities such as Saudi, Arab, Filipino Pakistani, Indian and Indonesian who are giving direct care to the patient and have more than 1year experience. All nurses who are not directly delivering nursing care, non-nursing staffs and nurses who are not willing to be the part of the study were excluded.

The job satisfaction measure contained 36 items that were categorized into eight items representing job satisfaction subscale that include (accommodation level), (administration and supervision), (work condition), (recognition), (co-workers communications), (educational activity), (payment) and (vacation and leave). A 4point likert-type scale (1) Satisfied (2) Average (3) Not-satisfied (4) Not-applicable used. Demographic information was collected using 11 items that's include: age, gender, nationality, marital status, nursing Qualifications, assignment area, type of contract, location of work, position, district of the work and year of experience. The questionnaire translated to Arabic language for Arabic speaking participates. The nurses how accepted to participate were asked to return the complete questionnaire to the researcher after filling online Google form through E-mail.

\section{Data analysis}

Data collected between September 2016 and November 2016. The total of the completed questionnaire received was 1037, and the rest did not return it for unknown reasons. Nevertheless, this considered appropriate for this type of studies. The obtained data is analyzed in terms of objectives by using (SPSS), version16. Descriptive statistics used to gather the information about nurse's job satisfaction.

\section{Results}

\subsection{Socio-demographic variables}

Study findings show that majority of the participants were females $(\mathrm{n}=773,74.54 \%)$ as presented in Table1.

The location of work optioned with hospitals and primary health centers. Among which the participants are more from hospitals $(\mathrm{n}=991,95.56 \%)$.

The other variable is regarding the participant's nationality which interprets that the Non-Saudi Non-Arab is the majority with $(\mathrm{n}=514,49.57 \%)$, Saudi $(\mathrm{n}=470,45.32)$ and Non-Saudi Arab $(\mathrm{n}=53,5.11 \%)$ as presented in Table1.

In terms of education. $43.20 \%$ were holding a nursing(NSG) diploma ( 2 years after high school), $3.38 \%$ holding a midwifery diploma, $6.46 \%$ holding associate(ASSO) degree, $45.13 \%$ holding a bachelor of nursing(BSN), $1.54 \%$ holding master of nursing(MSN) and $0.29 \%$ holding doctor of Philosophy (PhD) of nursing as presented in Table1.

The current position of the participants; staff nurse $(62.39 \%=$ $647)$, charge nurse $(18.51 \%=192)$, nursing supervisor $(7.14 \%=$ $74)$, nursing administration $(9.06 \%=94)$, director/deputy $(2.89 \%$ $=30$ ).

Marital status married $(65.67 \%=681)$, unmarried $(34.33 \%=356)$ as presented in Fig1.

Age distribution shows that $63.55 \%$ of nurses were between the ages of 25 to 34 , while $24.40 \mid \%$ were 35 to 44 years of age, $5.50 \%$ were younger than 24 years of age and $6.56 \%$ were older than 44 years of age as presented in Table1. No different were found according to age, gender, nationality, marital status, nursing qualifications, assignment area, type of contract, location of work, position, district of the work and year of experience. 


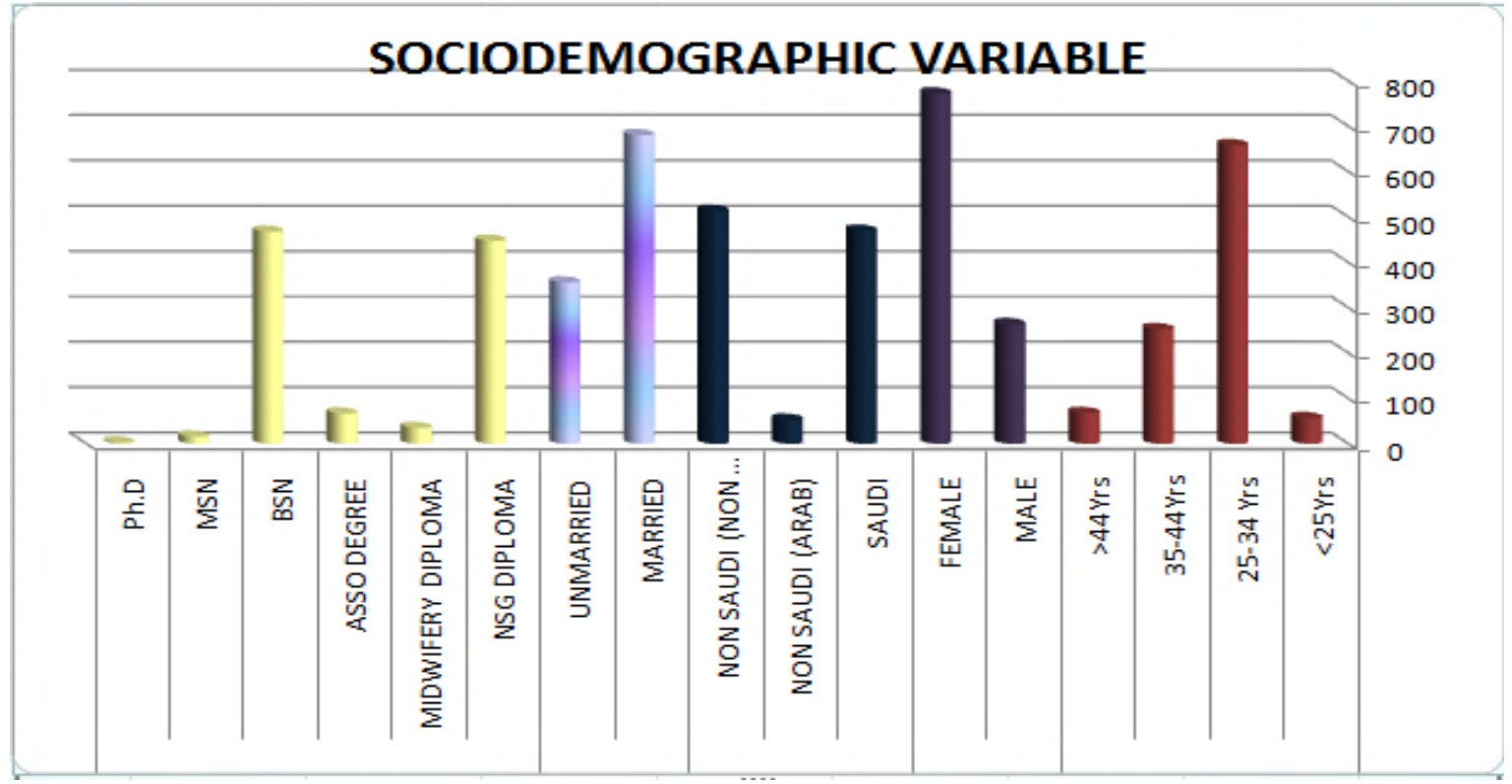

Fig. 1: Sociodemographic Variables.

Table 1: Sociodemographic Variables.

\begin{tabular}{|c|c|c|c|}
\hline Sociodemographic Variable & Categories & Frequency & Percentage \\
\hline \multirow{3}{*}{ 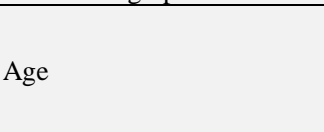 } & $<25 \mathrm{Yrs}$ & 57 & $5.50 \%$ \\
\hline & $25-34$ Yrs & 659 & $63.55 \%$ \\
\hline & $35-44$ Yrs & 253 & $24.40 \%$ \\
\hline \multirow{3}{*}{ Gender } & Male & 264 & $25.46 \%$ \\
\hline & Female & 773 & $74.54 \%$ \\
\hline & Saudi & 470 & $45.32 \%$ \\
\hline \multirow[t]{2}{*}{ Nationality } & Non-Saudi (Arab) & 53 & $5.11 \%$ \\
\hline & Non-Saudi (Non-Arab) & 514 & $49.57 \%$ \\
\hline \multirow{2}{*}{ Marital Status } & Married & 681 & $65.67 \%$ \\
\hline & Unmarried & 356 & $34.33 \%$ \\
\hline \multirow{6}{*}{ Educational Qualification } & NSG Diploma & 448 & $43.29 \%$ \\
\hline & Midwifery Diploma & 35 & $3.38 \%$ \\
\hline & ASSO Degree & 67 & $6.46 \%$ \\
\hline & BSN & 468 & $45.13 \%$ \\
\hline & MSN & 16 & $1.54 \%$ \\
\hline & $\mathrm{PhD}$ & 3 & $0.29 \%$ \\
\hline
\end{tabular}

Table 2: Items Representing Job Satisfaction

\begin{tabular}{|c|c|c|c|c|c|}
\hline Categories & Scale type & Frequency & Percent & Valid Percent & Cumulative Percent \\
\hline \multirow{4}{*}{$\begin{array}{l}\text { Satisfaction with administration } \\
\text { support }\end{array}$} & SATISFIED & 366 & 35.3 & 38.6 & 38.6 \\
\hline & AVERAGE & 344 & 33.2 & 36.2 & 74.8 \\
\hline & NOT-SATISFIED & 213 & 20.5 & 22.4 & 97.3 \\
\hline & NOT-APPLICABLE & 26 & 2.5 & 2.7 & 100.0 \\
\hline \multirow{4}{*}{$\begin{array}{l}\text { Satisfaction with accommoda- } \\
\text { tion utilities condition }\end{array}$} & SATISFIED & 77 & 7.4 & 14.0 & 14.0 \\
\hline & AVERAGE & 197 & 19.0 & 35.8 & 49.7 \\
\hline & NOT-SATISFIED & 203 & 19.6 & 36.8 & 86.6 \\
\hline & NOT-APPLICABLE & 74 & 74 & 13.4 & 100.0 \\
\hline \multirow{3}{*}{$\begin{array}{l}\text { Satisfaction with the staff num- } \\
\text { ber in unit }\end{array}$} & AVERAGE & 256 & 24.7 & 27.0 & 41.5 \\
\hline & NOT-SATISFIED & 443 & 42.7 & 46.7 & 88.2 \\
\hline & NOT-APPLICABLE & 112 & 10.8 & 11.8 & 100.0 \\
\hline \multirow{4}{*}{$\begin{array}{l}\text { Satisfaction with the ability to } \\
\text { discuss patient health issue with } \\
\text { other health care team members }\end{array}$} & SATISFIED & 422 & 40.7 & 44.5 & 44.5 \\
\hline & AVERAGE & 399 & 38.5 & 42.0 & 86.5 \\
\hline & NOT-SATISFIED & 87 & 8.4 & 9.2 & 95.7 \\
\hline & NOT-APPLICABLE & 41 & 4.0 & 4.3 & 100.0 \\
\hline \multirow{3}{*}{$\begin{array}{l}\text { Satisfaction with in-service } \\
\text { education activities in their } \\
\text { workplace }\end{array}$} & SATISFIED & 383 & 36.9 & 40.4 & 40.4 \\
\hline & NOT-SATISFIED & 162 & 15.6 & 17.1 & 97.2 \\
\hline & NOT-APPLICABLE & 27 & 2.6 & 2.8 & 100.0 \\
\hline \multirow{4}{*}{$\begin{array}{l}\text { Satisfaction with annual allow- } \\
\text { ance }\end{array}$} & SATISFIED & 225 & 21.7 & 23.7 & 23.7 \\
\hline & AVERAGE & 368 & 35.5 & 38.8 & 62.5 \\
\hline & NOT-SATISFIED & 309 & 29.8 & 32.6 & 95.0 \\
\hline & NOT-APPLICABLE & 47 & 4.5 & 5.0 & 100.0 \\
\hline
\end{tabular}

\subsection{Satisfaction with the administration}

addition, more than $50 \%$ they were satisfied with the nursing directors if they are willing to meet them as presented in Fig2.

Mostly, the nurses were satisfied with administrative support (mean=1.89 standard deviation $=0.842$ ) as shown in Table2. In 


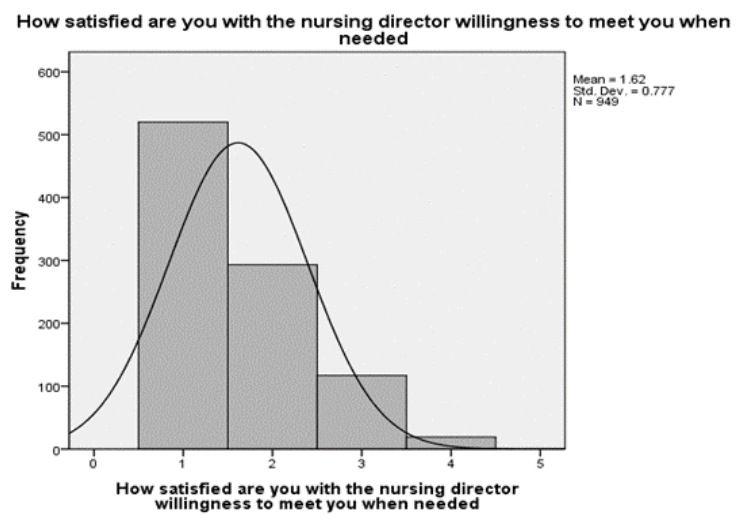

Fig. 2: Satisfaction with the Willing of Nursing Director to Meet Them If the Nurse Need.

\subsection{Satisfaction with the accommodation level}

Satisfaction with the accommodation mostly, was on average ring to satisfy and only $23.59 \%$ they were not satisfied.

The majority of the nurses not satisfied with the entertainment in the accommodation. More than $48.82 \%$ of the nurses were not satisfied by the accommodation utility's condition as shown in Table2.

\subsection{Satisfaction with work condition}

Mostly, they were satisfied with their work schedule, duty rotation, with nurse's assignments, time to perform nursing duties, availability of policy and procedures. Unfortunately, they were not satisfied by the staff number in unit and not enough to undertake all nursing work that percent in Table2.

\subsection{Satisfaction with recognition}

Mostly, they are happy with the appreciation and the recognition from the administration when doing the job well (main= 2.09 standard deviation $=0.955$ ) as presented in Fig3.

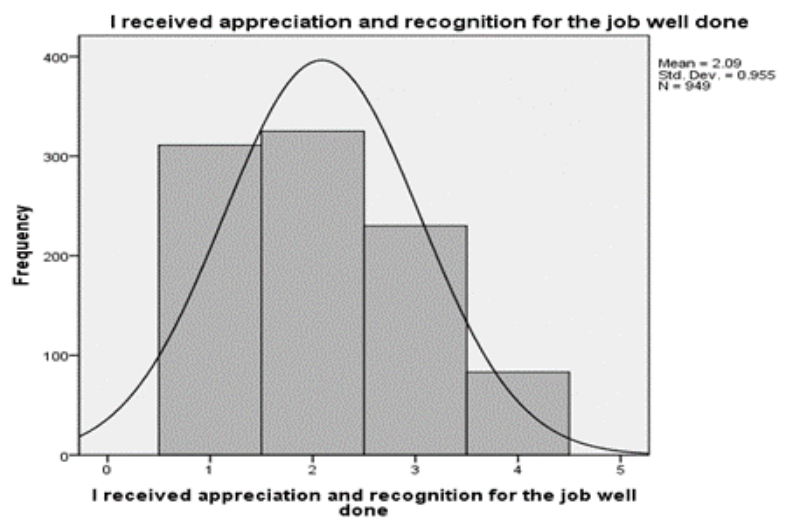

Fig. 3: Satisfaction with Recognition.

\subsection{Satisfaction with co-worker}

Only $11.91 \%$ said the doctors did not respect their contraptions in the treating plan (mean=1.79 standard deviation=0.814). Mostly, satisfied with their ability to discuss patient health issue with other health care team members as presented in Table2.

\subsection{Satisfaction with educational activity}

Generally, the nurses were satisfied with educational activity, i.e. they satisfied by the orientation program in their workplace $(\mathrm{n}=$ 949 mean=1.75 standard deviation=0.796). In addition, they satisfied with in-service educational activities in their workplace as shown in Table2. Furthermore, mostly they were moderately satis- fied with quality improvement activities ( $n=949$ mean=1.92 standard deviation $=0.799$ ).

\subsection{Satisfaction with payment and allowance}

Nurses were moderately satisfied with the salary amount as shown in Fig4. Mostly, nurses were moderately satisfied with annual allowance and many also not satisfied as presented in Table2.



Fig. 4: Satisfaction with Salary Amount.

\subsection{Satisfaction with vacation and leaves}

Mostly, were satisfied with their annual vacations as shown in Fig5. However, large number of nurses was not satisfied with their weekly off. In addition, many of them not satisfied with the number of the sick leaves given when they are sick as presented in Fig6.



Fig. 5: Satisfaction with Annual Vacation.

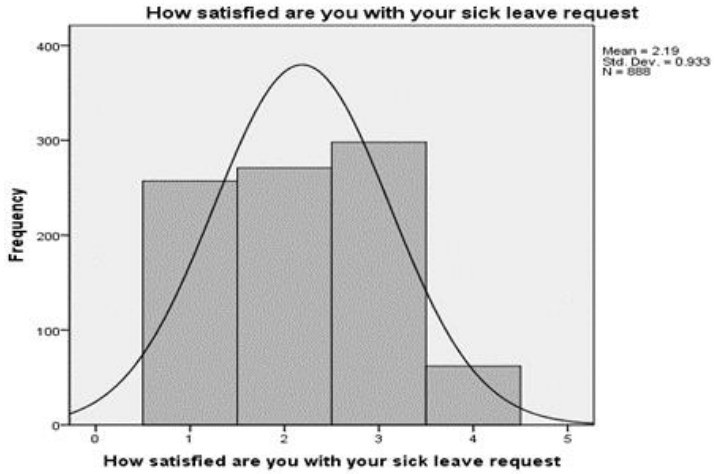

Fig. 6: Satisfaction with Sick Leave.

\section{Discussion}

This study set out to assess the job satisfaction, and the data analysis result was "somewhat satisfied" in general. A few nurses found not to be satisfied. This means that the environment and work nature were good enough for nurses. According to the study hospi- 
tals, officials should provide a good accommodation's utilities and to consider the level of entertainment in their accommodation as well as to provide more activities to develop the spirit of competition among hospital's nurses. Furthermore, they should find ways to increase the number of the nurse's staff within the unit to decrease the workload. In addition, many nurses want to receive more in annual allowances. Furthermore, the weekly off need to be revise by the officials of the hospital. Finally, hospitals should give more consideration to nurse's satisfaction due to its consequences(Al-Aameri, 2000).

\section{Acknowledgment}

This research was completed with the encouragement and support of group of people.

I would like to thank my co-investigators Mr. Adel Alhindi, Mr.Awad Alharbi and Mrs. Kavija Joshva for support and guiding me and will always be very grateful.

Thank you Dr. Ali A. Alakhafash, Dr. Abdullah M. Alsaigul, Dr.Amel A. Suliman and Dr. Mansour Alsoghair for support and help.

\section{References}

[1] Abualrub, R. F., \& Alghamdi, M. G. (2012). The impact of leadership styles on nurses satisfaction and intention to stay among Saudi nurses. Journal of Nursing Management, 20(5), 668-678. https://doi.org/10.1111/j.1365-2834.2011.01320.x.

[2] Al-Aameri, A. S. (2000). Job satisfaction and organizational commitment for nurses. Saudi Medical Journal, 21(6), 531-535.

[3] Al-Ahmadi, H. (2009). Factors affecting performance of hospital nurses in Riyadh Region, Saudi Arabia. International Journal of Health Care Quality Assurance, 22(1), 40-54. https://doi.org/10.1108/09526860910927943.

[4] AL-Dossary, R., Vail, J., \& Macfarlane, F. (2012). Job satisfaction of nurses in a Saudi Arabian university teaching hospital: a crosssectional study. International Nursing Review, 59(3), 424-430. https://doi.org/10.1111/j.1466-7657.2012.00978.x.

[5] Alam, M. M., \& Mohammad, J. F. (2010). Level of job satisfaction and intent to leave among Malaysian nurses. Business Intelligence Journal, 3(1), 123-137.

[6] Asegid, A., Belachew, T., \& Yimam, E. (2014). Factors influencing job satisfaction and anticipated turnover among nurses in Sidama zone public health facilities, South Ethiopia. Nursing Research and Practice, 2014. https://doi.org/10.1155/2014/909768.

[7] Baernholdt, M., \& Mark, B. A. (2009). The nurse work environment, job satisfaction and turnover rates in rural and urban nursing units. Journal of Nursing Management, 17(8), 994-1001. https://doi.org/10.1111/j.1365-2834.2009.01027.x.

[8] Coomber, B., \& Barriball, K. L. (2007). Impact of job satisfaction components on intent to leave and turnover for hospital-based nurses: a review of the research literature. International Journal of Nursing Studies, 44(2), 297-314. https://doi.org/10.1016/j.ijnurstu.2006.02.004

[9] Cortese, C. G. (2007). Job satisfaction of Italian nurses: an exploratory study. Journal of Nursing Management, 15(3), 303-312. https://doi.org/10.1111/j.1365-2834.2007.00694.x.

[10] El Gilany, A., \& Al Wehady, A. (2001). Job satisfaction of female Saudi nurses.

[11] Kettle, J. L. (2002). Factors affecting job satisfaction in the registered nurse. Journal of Undergraduate Nursing Scholarship, 4(1), 14.

[12] Lu, H., While, A. E., \& Louise Barriball, K. (2005). Job satisfaction among nurses: A literature review. International Journal of Nursing Studies. https://doi.org/10.1016/j.ijnurstu.2004.09.003.

[13] Mitchell, J. E. (2009). Job satisfaction and burnout among foreigntrained nurses in Saudi Arabia: A mixed-method study. University of Phoenix.

[14] Zaghloul, A. A., Al-Hussaini, M. F., \& Al-Bassam, N. K. (2008). Intention to stay and nurses satisfaction dimensions. Journal of Multidisciplinary Healthcare, $\quad 1, \quad 51$. https://doi.org/10.2147/JMDH.S3804. 